\title{
Hormonal and modality specific effects on males' emotion recognition ability
} Adi Lausen*1,3, Christina Broering ${ }^{1}$, Lars Penke ${ }^{2,3}$, Annekathrin Schacht ${ }^{1,3}$

${ }^{1}$ Department of Affective Neuroscience and Psychophysiology, Institute for Psychology, University of Goettingen, 37073 Goettingen, Germany

${ }^{2}$ Department of Biological Personality Psychology, Institute for Psychology, University of Goettingen, 37073 Goettingen, Germany

${ }^{3}$ Leibniz ScienceCampus “Primate Cognition”, 37077 Goettingen, Germany

*Email: adi.lausen@psych.uni-goettingen.de 


\section{Abstract}

1 Successful emotion recognition is a key component of our socio-emotional communication

2 skills. However, little is known about the factors impacting males' accuracy in emotion

3 recognition tasks. This pre-registered study examined potential candidates, focusing on the

4 modality of stimulus presentation, emotion category, and individual hormone levels. We

5 obtained accuracy and reaction time scores from 312 males who categorized voice, face and

6 voice-face stimuli for nonverbal emotional content. Results showed that recognition accuracy

7 was significantly higher in the audio-visual than in the auditory or visual modality. While no

8 significant association was found for testosterone and cortisol alone, the effect of the interaction

9 with recognition accuracy and reaction time was significant, but small. Our results establish

10 that audio-visual congruent stimuli enhance recognition accuracy and provide novel empirical

11 support by showing that the interaction of testosterone and cortisol modulate to some extent

12 males' accuracy and response times in emotion recognition tasks.

13 Keywords: Emotion Recognition, Prosody, Facial Expressions, Testosterone, Cortisol, Dual14 hormone hypothesis 


\section{Introduction}

1 Emotion recognition is a basic skill thought to carry clear advantages for predicting behaviour,

2 as well as forming and maintaining social bonds (Soto \& Levenson, 2009). Intriguingly,

3 research on sex differences highlights that males are less accurate than females when

4 completing emotion recognition tasks (e.g., Thompson \& Voyer, 2014; Hall, 1984). However,

5 effect sizes are comparably small and multiple factors known to impact the ability to recognize

6 emotions have yet to be fully controlled for (e.g., Hall et al., 2000; see Chaplin, 2015; Fischer,

$7 \quad \&$ LaFrance, 2015; Hyde, 2014; Schirmer, 2013, for an overview regarding explanations for

8 sex-based behaviour patterns). The ability to correctly interpret emotional expressions forms

9 the basis of social interactions and personal relationships (e.g., Fischer \& Manstead, 2008;

10 Keltner \& Kring, 1998) yet, there is a lack of direct evidence for reasons why males have an

11 often assumed disadvantage when it comes to accurately recognizing emotions. Therefore, the main aim of this study was to systematically investigate potential factors that might impact

13 males' ability to recognize emotions.

14 One of the factors supposed to impact emotion recognition is the modality of stimulus 15 presentation (Hall, 1984). In many everyday situations, judgments about others' emotional states require the integration of information from various sensory modalities making use of 17 different cues such as facial expressions, tone of voice (i.e., prosody), or body language (Klasen et al., 2014). Thus, it has been argued that emotion recognition is a multimodal event (Piwek et al., 2015). Indeed, a growing number of studies have pointed out that in emotion recognition tasks the stimuli presented in isolation (i.e., visual or auditory) have lower accuracy scores and 21 slower response times than the audio-visual presentation of emotional expressions (Jessen et al., 2012; Paulmann \& Pell, 2011; Baenziger et al., 2009; Collignon et al., 2008; Kreifelts et al., 2007; de Gelder \& Vroomen, 2000). Research on unimodal emotion recognition reported

24 that emotions are better recognized from faces than from voices (e.g., Waaramaa, 2017). 
1 However, these observations were often contradictory (e.g., Kraus, 2017). Furthermore,

2 previous research in the unimodal domains highlighted that specific emotions are not

3 recognized equally well in the auditory and visual modality. In studies on the vocal channel,

4 participants were faster and most accurate to recognize anger (e.g., Chronaki et al., 2018;

5 Cornew et al., 2009; Juslin \& Laukka, 2003), while in studies on facial expressions, happiness

6 was shown to be recognized more accurately and faster than any other emotion (e.g.,

7 Kosonogov \& Titova, 2018; Wells et al., 2016; Nummenmaa \& Calvo, 2015; Williams et al.,

8 2009; Montagne et al., 2007; Palermo \& Coltheart, 2004; Elfenbein \& Ambady, 2002). Despite

9 these converging patterns, it is as yet not possible to make definite claims regarding the

10 advantage of certain emotional categories because, at least within the vocal domain, recognition

11 accuracy (RA) was found to be strongly influenced by the type of stimulus used (see Lausen et

12 al., 2019, for an overview). Whether the voice is a more reliable source than the face in emotion

13 recognition tasks has been rarely pursued, and results are limited to specific emotions,

14 paradigms, as well as, by a number of methodological differences between studies. Thus, until

15 further evidence regarding RA within specific sensory modalities and emotional categories is

16 provided, the direction of these effects remains an open question.

17 A recently emphasized influence on the ability to recognize emotions concerns potential effects of steroid hormones, such as testosterone (Gignell et al., 2019). Testosterone (T) receptors are distributed throughout the nervous system with high concentrations in areas associated with emotional processing such as the hypothalamus and amygdala [see Gignell et al., 2019, for 21 details]. However, only few studies have assessed the influence of T concentrations on emotion recognition in both sexes and an even smaller subsection has specifically addressed the impact of T levels on males' ability to recognize emotions. For example, an fMRI study by Derntl et al. (2009) investigated the influence of blood T levels on males' RA in an explicit emotion 
1 during the presentation of fearful and angry faces. In addition, the authors found that reaction

2 times (RTs) to fearful male faces negatively correlated with T level concentrations. However,

3 no correlation was found between RA and T levels. Subsequent studies reported a negative

4 correlation between salivary $\mathrm{T}$ levels and emotion recognition in male adolescent groups

5 (Fujisawa \& Shinohara, 2011) or found a positive correlation between higher levels of T and

6 emotion recognition (Vongas \& Al Hajj, 2017). By presenting participants with emotional

7 facial expressions at two different intensity levels (i.e., 50\% and 100\%), Rukavina et al. (2018)

8 found that RA decreases when salivary $\mathrm{T}$ is high, especially for full-blown expressions of

9 sadness and for disgust when presented at 50\% intensity. Based on these findings, the authors

10 concluded that RA decreases with increasing levels of $\mathrm{T}$.

11 These contradictory findings are likely the result of a number of methodological differences 12 such as insufficient statistical power (i.e., sample sizes ranging from 21 to 84 males), $\mathrm{T}$ assessment from blood or saliva, as well as storage and analyses of hormone samples (see Schultheiss et al., 2019, for details). Another possible explanation for the discrepancies is that another hormone, cortisol (C), may constrain $\mathrm{T}$ influence on emotion recognition. $\mathrm{C}$, an end product of the hypothalamic-pituitary-adrenal (HPA) axis, was found to inhibit $\mathrm{T}$ by reducing hypothalamic-pituitary-gonadal (HPG) activity and blocking androgen receptors [see Sarkar et al., 2019; Viau, 2002, for details]. To reconcile mixed findings on the roles of T and C in human social behavior, Mehta and Josephs (2010) proposed the dual-hormone hypothesis. According to this hypothesis $\mathrm{T}$ predicts a wide range of behaviors, but only under the condition that $\mathrm{C}$ concentrations are low. If $\mathrm{C}$ concentrations are high, the $\mathrm{T}$-behavior association is supposed to be attenuated (Mehta \& Prasad, 2015; Carré \& Mehta, 2011). This hypothesis was supported in a variety of studies, which demonstrated that across different psychological domains the interaction between $\mathrm{T}$ and $\mathrm{C}$ influences empathy, as well as, dominant, status-relevant, risk- 
1 noted that other studies report only small effects (e.g., Dekkers et al., 2019; Grebe et al., 2019)

2 null-findings [e.g., Mazur \& Booth, 2014], and even reversed patterns [i.e., T was related to

3 status-relevant behavior or facial dominance for high but not low C (e.g., Kordsmeyer et al.,

4 2018; Welker et al., 2014)] for the dual-hormone hypothesis. Considering the interaction

5 between the HPG and HPA axes might nevertheless lead to more reliable predictions regarding

6 emotion recognition than the assumption of a single-hormone association (Sarkar et al., 2019;

7 Carré \& Mehta, 2011).

8 Based on the above-mentioned findings, the present study had three major aims. Firstly, it

9 aimed at examining whether males' RA is influenced by the modality of stimulus presentation.

10 We hypothesized that RA would be better in the audio-visual modality than in the auditory or

11 visual modality (1a), and lower in the visual compared to the auditory modality (1b). Second, we aimed to replicate previous findings by examining the extent RA and RTs vary across discrete emotion categories as a function of modality (e.g., Lambrecht et al., 2014). Specifically, we expected higher accuracy scores and faster RTs for disgusted, fearful and sad expressions in the audio-visual than in both the auditory and the visual modality (2a). We also hypothesized that angry expressions would be identified faster and with higher accuracy in the vocal compared to the facial domain, while for happy expressions we expected the reverse pattern (2b). A third aim was to alleviate some of the methodological flaws of previous research by using a large sample size to examine whether variations in males' ability to recognize emotions are due to $\mathrm{T}$ level concentrations. We expected a negative correlation between $\mathrm{T}$ and RA (3a), and that participants with high levels of T would specifically react faster to angry and fearful expressions $(3 b)^{1}$. In addition, we conducted an exploratory analysis on the associations between $\mathrm{C}$ and RA, C and RT, as well as on the relationship between RA or RT and the interaction between $\mathrm{T}$ and $\mathrm{C}$ levels.

\footnotetext{
${ }^{1}$ All hypotheses tested in the current paper have been pre-registered (osf.io/w2tgr). This pre-registration contained further hypotheses that are not part of the present paper.
} 


\section{Method}

1 The study was approved by the ethics committee of the Georg-Elias-Mueller-Institute of

2 Psychology (University of Goettingen), and conducted in accordance with the ethical principles

3 formulated in the Declaration of Helsinki (2013). Participants gave informed consent and were

4 reimbursed with course credit or 8 Euros per hour.

\section{Participants}

5 A total of 312 males (age range $18-36$ years; $M_{\text {Age }}=24.3, S D=3.7$ ) were recruited on the

6 university campus using flyers and the Institute of Psychology participant database (ORSEE,

7 www.orsee.org), as well as by posts on the social media site Facebook and the online platform

8 Stellenwerk Jobportal University Goettingen (www.stellenwerk-goettingen.de). Of the 312

9 recruited subjects, 30 participants were excluded from analysis due to self-reported hearing

10 problems, psychiatric or neurological disorders, or intake of psychotropic/hormone medication.

11 After these exclusions, a total of 282 participants with a mean age of 24.3 years $(S D=3.8)$ were

12 included in the analysis.

\section{Stimulus material}

13 Stimuli were displayed under three experimental modality conditions: auditory, visual and

14 audio-visual. In each experimental condition, stimuli were presented in one of the emotions of interest (i.e., anger, disgust, fear, happiness, sadness) as well as in a neutral state (i.e., baseline

16 expression).

\section{Audio stimuli}

17 The audio stimuli consisted of pseudo-speech (i.e., pseudo-words, pseudo-sentences) and non-

18 verbal vocalizations (i.e., affect bursts). We decided to use pseudo-speech (i.e., a language

19 devoid of meaning) and non-verbal vocalizations as they have been argued to capture the pure

20 effects of emotional prosody independent of lexical-semantic cues and, to be an ideal tool when

21 investigating the expression of emotional information when there is no concurrent verbal 
1 information present (Pell et al., 2015; Banse \& Scherer, 1996). The stimuli were sampled from

2 well-established databases or provided by researchers who developed their own stimulus

3 materials. We validated all stimuli in a previous study (cf. Lausen et al., 2019; Lausen \&

4 Schacht, 2018) and selected only a subset of stimuli (i.e., with the highest accuracy) from each

5 database (see Table 1).

\begin{tabular}{|c|c|c|c|c|c|}
\hline Database & Speakers & Emotions & Nature of material & $\begin{array}{c}\text { Number of } \\
\text { stimuli selected }\end{array}$ & Total stimuli \\
\hline $\begin{array}{c}\text { Magdeburg Prosody Corpus } \\
\text { (Wendt \& Scheich, 2002) }\end{array}$ & $\begin{array}{c}2 \text { actors } \\
(1 \text { male/1 female })\end{array}$ & & Pseudo-words & 4 & 48 \\
\hline $\begin{array}{l}\text { Paulmann Prosodic Stimuli } \\
\text { (Paulmann \& Kotz, 2008; } \\
\text { Paulmann et al., 2008) }\end{array}$ & $\begin{array}{c}2 \text { actors } \\
\text { (1 male/1 female) }\end{array}$ & $\begin{array}{l}\text { Anger, disgust, } \\
\text { fear, happiness, } \\
\text { sadness, neutral }\end{array}$ & Pseudo-sentences & 4 & 48 \\
\hline $\begin{array}{c}\text { Montreal Affective Voices } \\
\text { (Belin et al., 2008) }\end{array}$ & $\begin{array}{c}8 \text { actors } \\
(4 \text { male } / 4 \text { female })\end{array}$ & & Affect bursts & & 48 \\
\hline
\end{tabular}

6 The physical volume of stimulus presentations across the nine laptops used in the experiment

7 was controlled by measuring sound volume of the practice trials with a professional sound level

8 meter, Nor140 (Norsonic, 2010, Lierskogen, Norway). No significant difference in volume

9 intensity was observed $\left[F_{(8,40)}=1.546, p=0.173\right]$.

\section{Visual stimuli}

10 Visual stimuli consisted of 24 frontal face photographs (12 males/12 females) extracted from

11 the Radboud Faces Database (Langner et al., 2010). The presentation time of the faces was matched to the length of the voice stimuli (i.e., from $319 \mathrm{~ms}$ to $4821 \mathrm{~ms}$ ). A gray ellipsoid mask,

13 ensuring a uniform figure/ground contrast surrounded the stimuli, with only the internal area of

14 the face visible $(9 \times 14 \mathrm{~cm}$, width and height). The stimuli were presented in colour and corrected

15 for luminance across emotion conditions $\left[F_{(5,137)}=0.200, p=0.962\right]$, using Adobe Photoshop

16 CS6 (Version 13.0.1, 2012, San Jose, CA).

\section{Audio-visual stimuli}

17 The voice stimuli were simultaneously presented with the face stimuli. Using Adobe Premiere 18 Pro CS6 (Version 6.0.5) videos were created, matching face and voice stimuli for sex and 19 emotion category. 


\section{Procedure, experimental task and saliva samples}

1 Participants were informed that the study required them to provide two saliva samples over a

2 period of about two hours. A day before the main experiment, they were sent an email

3 instructing them to abstain from sports and the consumption of alcohol, drugs or unnecessary

4 medication on the day of the study. Furthermore, they were instructed not to consume drinks

5 containing caffeine within three hours of the experiment and to refrain from eating, drinking

6 (except water), smoking and brushing their teeth within one hour of the experiment. Adherence

7 to these instructions was assessed using a screening questionnaire (Schultheiss \& Stanton,

8 2009). As individual differences in peak hormone levels measured in the morning have been

9 argued to be a better predictor of behavioural responses to emotional stimuli than measurements

10 later in the day (Schultheiss \& Stanton, 2009), the designated time slot for testing was between

$119: 00$ am to 11:00am.

12 Participants were tested in groups of up to nine individuals. On the day of the study, after

13 completing the consent form, participants received oral and written instructions about the

14 procedure of the experiment and the collection of saliva samples. The saliva samples were

15 collected before (T1) and after (T2) the Emotion Recognition Task ${ }^{2}$. The experiment was programmed using Python (Version 2.7.0, Python Software Foundation, Beaverton, OR) and run on a Dell Latitude E5530 Laptop with a 15.6 LCD display screen. The audio stimuli were presented binaurally via headphones (Bayerdynamic DT 770 PRO).

\footnotetext{
2 The data reported in this paper was obtained within the confines of a larger study. The experiment began with a short demographic questionnaire followed by the Screening Questionnaire (Schultheiss \& Stanton, 2009), MultiMotive Grid [MMG, Sokolowski et al., 2000] and Positive and Negative Affect Schedule [PANAS, Breyer \& Bluemke, 2016]. Next, the first saliva sample (T1) was taken. After a short break, the Emotion Recognition Task ensued, followed by PANAS, and the collection of the second saliva sample (T2). The saliva samples were collected approximately 10 minutes before and after the emotion recognition task. The experiment ended with the completion of Multifaceted Empathy Test short-form [MET, Dziobek et al., 2008] and Big Five Inventory [BFI, Danner et al., 2016]. As MMG, PANAS, MET and BFI are not relevant to the present manuscript they are not further reported.
} 


\section{Emotion recognition task}

1 The emotion recognition task consisted of three blocks, each block displaying one of the three

2 experimental conditions: auditory, visual, and audio-visual. Each experimental condition

3 contained 144 stimuli. A permutation was applied to randomize the order in which the

4 experimental conditions were presented to the participants. Six different permutations were

5 created, and each permutation was allocated randomly in blocks of six participants. The order

6 of the stimuli within each experimental condition was completely randomized. The audio and

7 visual stimuli were matched for duration, sex, and emotion category (see Table S1 in

8 supplementary material for an example of how the audio and visual stimuli were matched).

9 Before each experimental condition, participants were familiarized with the task in a short

10 training session comprised of three stimuli. Each trial began with a blank screen followed by a

11 fixation cross. Following the presentation of a stimulus, a circular answer display appeared, containing all six categories of interest (i.e., anger, disgust, fear, happiness, sadness, neutral)

13 and the selection cursor, which appeared in the centre of the display. The sequence of the

14 emotion labels was randomized for each participant and remained the same throughout the task.

15 Participants had to select an emotion category, using the mouse to move the cursor, before the next stimulus was presented. Reaction times were measured, starting with the onset of the

17 answer display and ending with the participant's response. Figure 1 displays the time course

18 of the emotion recognition task.

\section{Saliva samples}

19 The two saliva samples ( $2 \mathrm{ml}$ per sample) were collected from each participant via passive drool 20 through a straw (Schultheiss et al., 2012) into an IBL SaliCap sampling device. These plastic 21 vials were stored frozen at $-80^{\circ} \mathrm{C}$ until shipment on dry ice to the Endocrinology Laboratory at 22 Technical University of Dresden. At this facility, the samples were analysed for $\mathrm{T}$ and $\mathrm{C}$ levels 23 via chemiluminescence immunoassays with high sensitivity (IBL International, Hamburg, 
1 Germany). The intra- and inter-assay coefficients of variation for $\mathrm{T}$ were $<11 \%$ and for $\mathrm{C}<$

$28 \%$. For $\mathrm{T}$ the variance between participants was $14.81 \%$ and $3.85 \%$ within participants with

3 an intra-class correlation coefficient (ICC) of 79.35\%, while for $\mathrm{C}$ the variance between

4 participants was $23.78 \%$ and $28.20 \%$ within participants with an ICC of $45.74 \%$. As the

5 distributions of $\mathrm{T}$ and $\mathrm{C}$ were positively skewed $\left(\mathrm{T}_{\text {skewness }}=1.56 ; \mathrm{C}_{\text {skewness }}=1.49\right) \mathrm{a} \log$ -

6 transformation was performed (e.g., Mehta et al., 2015). The log-transformation reduced

7 skewness substantially $[\log (\mathrm{T})$ skewness $=-0.06 ; \log (\mathrm{C})$ skewness $=0.01]$. Outliers were

8 winsorized to \pm 3 standard deviations (Mehta et al., 2015).

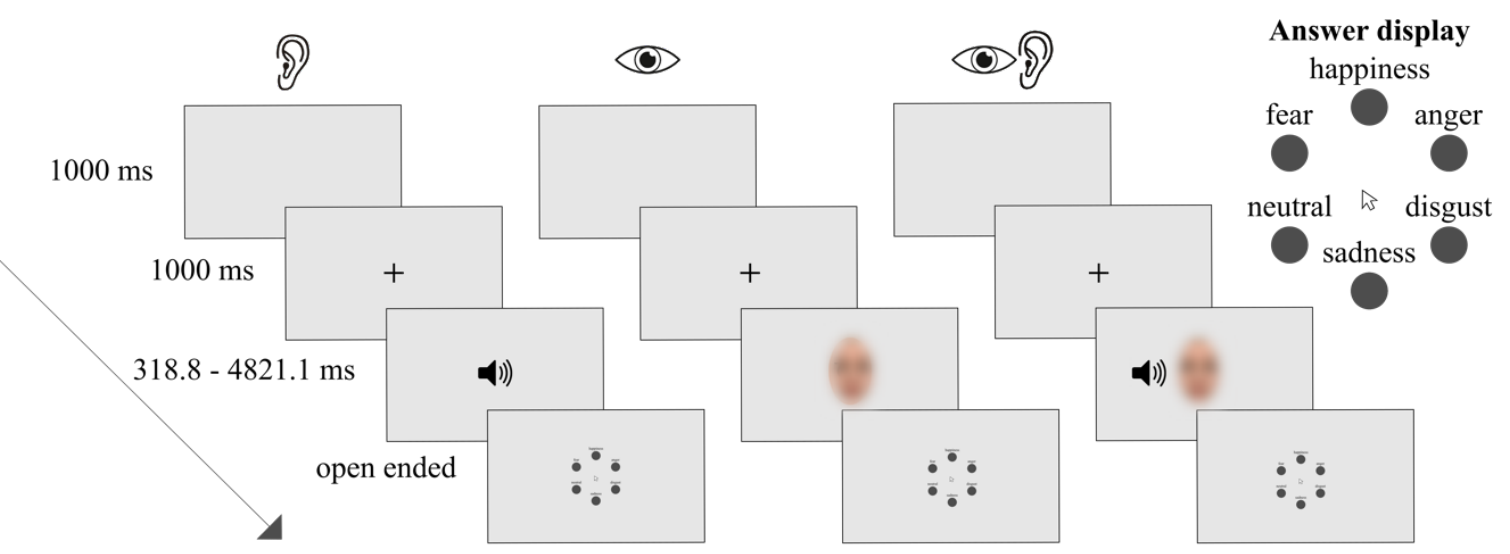

Figure 1 | Emotion recognition task

Each trial began with a blank screen (shown for 1000ms) which was followed by a fixation-cross appearing at the center of the screen (for $1000 \mathrm{ms)} \mathrm{at}$ which participants were asked to fixate throughout the trial. After the presentation of the stimulus a circular answer display containing all six categories of interest (i.e., anger, disgust, fear, happiness, sadness, neutral) and the selection cursor (which appeared in the center of the display) were presented. The responses were made by using the mouse to move the cursor. Reaction times were measured, starting with the onset of the answer display and ending with the participant's response. There was no time limit for emotion judgments. Participants could hear/see the stimulus only once. The presentation of the stimuli was initiated by pressing the Spacebar-key at the beginning of each block. At the end of each block a visual message in the center of the screen instructed participants to take a break if they wished to or to press the Spacebar-key to proceed with the next block. (The face stimuli were obscured as per bioRxiv policy)

\section{Study design and power analysis}

12 A balanced within-subjects factorial design was fitted to assess males' judgments of emotions.

13 The design was balanced for modalities, emotion categories and encoder sex in each stimulus

14 type. Independent within-participant factors were modalities, emotion categories, stimuli types, 
1 A target sample size of 231 males was determined using an approximate correlation power

2 analysis, Bonferroni-corrected for multiple testing $(r=.25 ; \alpha=.05 / 20 ; 1-\beta=.80)$. To account

3 for possible attrition, the sample size was increased by a minimum of $14 \%$.

\section{Statistical analysis}

4 In line with our preregistration, the primary analysis for our first and second hypotheses was

5 performed using Friedman- and Wilcoxon-rank-sum tests. For the association between the

6 dependent variables (RA, RT) and T levels we ran Spearman correlations (H3a, b).

7 The exploratory analyses of the quantitative variables $\mathrm{T}$ and $\mathrm{C}$ were performed using generalized linear models (quasi-binomial logistic regression) for the binary response variable emotion recognition and linear models for the response variable reaction time, which was normalized by log transformation. To obtain a more reliable value and to cover the observation

11 interval, the two baseline measures for $\mathrm{T}$ and $\mathrm{C}$ were averaged (Kordsmeyer et al., 2018; Idris et al., 2017). The dispersion parameter of the quasi-binomial model accounted for dependencies

13 caused by repeated measurements within the participants. Modality and emotion category were

14 fitted as nominal variables and stimulus duration as quantitative variable. The interaction of the quantitative variables $\mathrm{T}$ and $\mathrm{C}$ was fitted by the product of both variables as an additional predictor. Tertiles for both variables, $\mathrm{T}$ and $\mathrm{C}$, were fitted to investigate more general interaction patterns and to reduce the influence of $\mathrm{T}$ and $\mathrm{C}$ extreme values on the model equation. Chisquare tests of the deviance analysis and F-tests of the analysis of variance were used to analyse effects of predictor variables. In the quasi-binomial logistic regression, odds ratio (OR) were used to compare emotion recognition accuracies. RTs were compared by the difference of the

21 means. Tukey's method of multiple pairwise comparisons was used to compute simultaneous $95 \%$ confidence intervals for both, OR and mean differences.

For the descriptive analysis of the data, relative frequencies, confusion matrices and Wagner's

24 (1993) unbiased hit rate $\left(H_{u}\right)$, which is the rate of correctly identified stimuli multiplied by the 
1 rate of correct judgments of the stimuli, were calculated. The data was analysed using the $\mathrm{R}$

2 language and environment for statistical computing and graphics version 3.4.3 (R Core Team,

3 2017) and the integrated environment R-Studio version 1.0.153 (used packages: $p w r ;$ MASS;

4 coin; glm; multcomp; mvtnorm; ggplot2).

\section{Results}

\section{Descriptive analysis}

5 Audio-visual emotional expressions were recognized with approximately $90 \%$ accuracy

6 (lowest identification rate $89 \%$ for disgust). Angry expressions were recognized with better 7 accuracy from the voice (90\%) than the face (82\%). Conversely, for fearful, happy and sad 8 expressions accuracy scores were higher when presented visually $(85 \% \leq$ accuracy scores $\leq$ $999 \%)$ than auditorily ( $72 \% \leq$ accuracy scores $\leq 77 \%)$. Neutral expressions had high accuracy

10 scores in all three conditions of stimulus presentation $(90 \% \leq$ accuracy scores $\leq 95 \%)$.

11 Participants were faster at recognizing disgust, fear, happy, sad and neutral expressions in the

12 visual and audio-visual modalities (median $(M d)$ values between $1.03 \mathrm{sec}$. to $1.46 \mathrm{sec}$.) than in

13 the auditory modality ( $M d$ values between $1.50 \mathrm{sec}$. to $1.95 \mathrm{sec}$.). Although the RTs for

14 disgusted, sad and neutral expressions were similar in the visual and audio-visual modalities, participants were slightly faster at recognizing fear and happy in the visual than audio-visual modality. For angry expressions, the RTs were much shorter in the audio-visual $(1.23 \mathrm{sec}$.$) than$

17 in the auditory and visual modality, but much longer in the visual (1.53 sec.) than in the auditory modality (1.47 sec.). Figure 2 illustrates participants' RA (panel A) and RTs (panel B) by 19 modality and emotion categories.

20 In all three modalities participants often misclassified happy and sad expressions as neutral. In 21 the auditory and audio-visual modalities angry was mistaken for fearful, neutral for angry and 22 fearful for sad. In the visual modality fear was confused with disgust, whereas anger and neutral 23 were confused with sadness. Participants frequently misclassified disgust with anger in the 
(A)

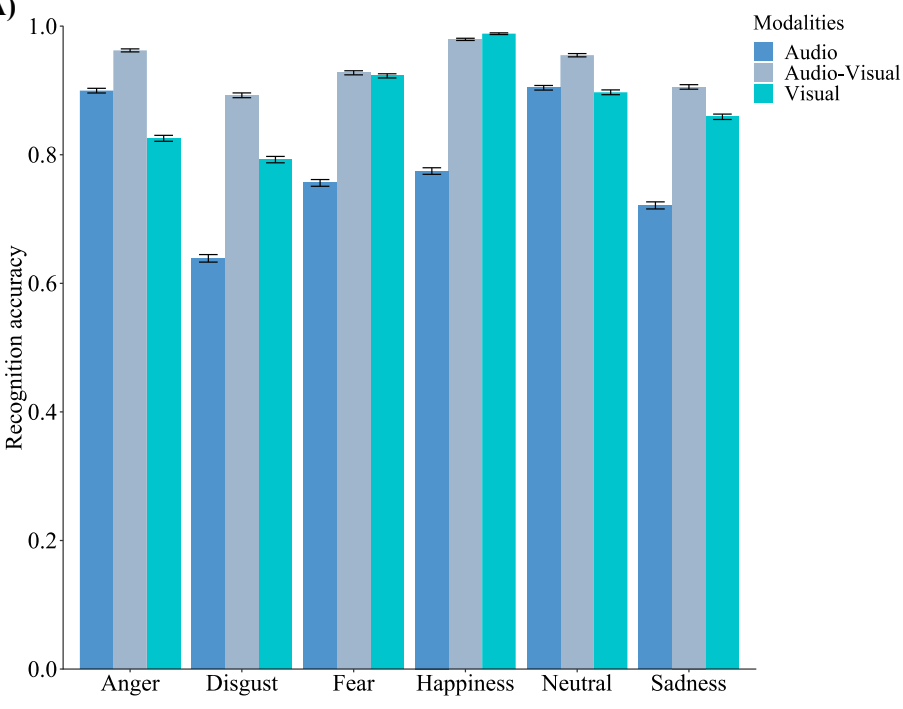

(B)

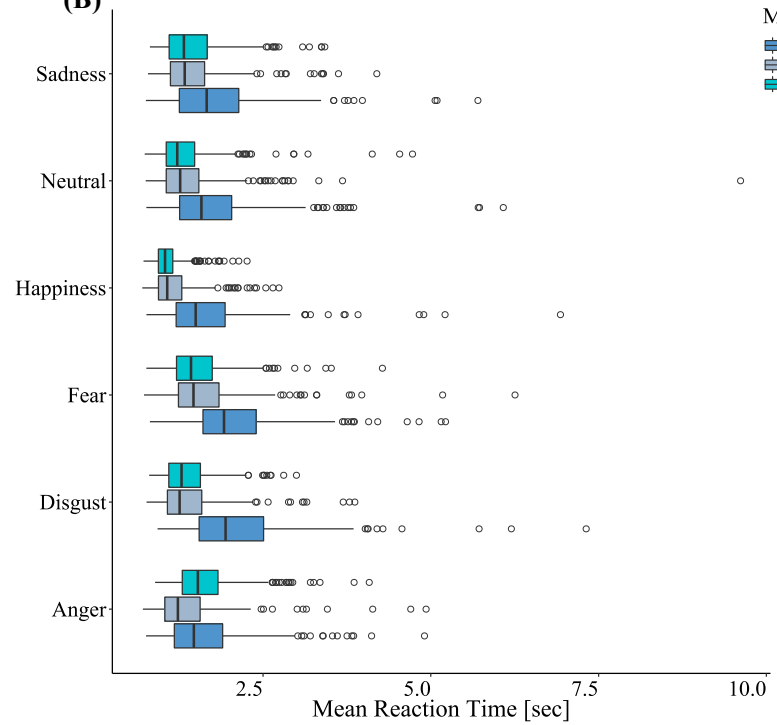

Modalities

Figure 2 | Recognition accuracy (RA) and reaction times (RTs) by modality and emotion categories

The bar charts (panel A) display RA, while the boxplots (panel B) illustrate the mean RT distributions. Error bars represent the standard error. The boxplots indicate that the distributions of RT are right skewed.

1 visual and audio-visual modalities, while in the auditory modality disgust was mistaken for

2 neutral. The error classification patterns along with the unbiased hit rates are presented in Table

32.

Table 2 Confusion Matrices and unbiased hit rates $\left(H_{u}\right)$ for participants judgments of emotion categories

\begin{tabular}{|c|c|c|c|c|c|c|c|c|c|}
\hline \multirow[t]{2}{*}{ Modality } & \multirow[t]{2}{*}{ Emotions portrayed } & \multicolumn{8}{|c|}{ Emotion judgments } \\
\hline & & Anger & Disgust & Fear & Happiness & Neutral & Sadness & Total & $H_{u}$ \\
\hline \multirow{7}{*}{ Auditory } & Anger & 6089 & 59 & 267 & 152 & 175 & 26 & 6768 & .766 \\
\hline & Disgust & 347 & 4324 & 438 & 280 & 815 & 564 & 6768 & .590 \\
\hline & Fear & 162 & 173 & 5118 & 96 & 406 & 813 & 6768 & .621 \\
\hline & Happiness & 116 & 27 & 15 & 5243 & 1335 & 32 & 6768 & .665 \\
\hline & Neutral & 339 & 52 & 62 & 159 & 6119 & 37 & 6768 & .549 \\
\hline & Sadness & 97 & 50 & 335 & 175 & 1230 & 4881 & 6768 & .554 \\
\hline & Total & 7150 & 4685 & 6235 & 6105 & 10080 & 6353 & 40608 & - \\
\hline \multirow{7}{*}{ Visual } & Anger & 5587 & 244 & 194 & 6 & 234 & 503 & 6768 & .638 \\
\hline & Disgust & 1288 & 5363 & 48 & 13 & 41 & 15 & 6768 & .704 \\
\hline & Fear & 51 & 282 & 6245 & 14 & 73 & 103 & 6768 & .847 \\
\hline & Happiness & 6 & 2 & 11 & 6689 & 59 & 1 & 6768 & .967 \\
\hline & Neutral & 167 & 15 & 47 & 102 & 6071 & 365 & $6767^{*}$ & .791 \\
\hline & Sadness & 135 & 134 & 262 & 11 & 412 & 5814 & 6768 & .734 \\
\hline & Total & 7234 & 6040 & 6807 & 6835 & 6890 & 6801 & 40607 & - \\
\hline \multirow{7}{*}{ Audio-visual } & Anger & (6513 & 46 & 91 & 8 & 71 & 39 & 67678 & 2.860 \\
\hline & Disgust & 505 & 6040 & 69 & 14 & 81 & 59 & 6768 & .858 \\
\hline & Fear & 39 & 155 & 6277 & 9 & 92 & 196 & 6768 & .873 \\
\hline & Happiness & 5 & 2 & 7 & 6629 & 121 & 4 & 6768 & .969 \\
\hline & Neutral & 170 & 11 & 25 & 35 & 6462 & 65 & 6768 & .859 \\
\hline & Sadness & 55 & 27 & 196 & 9 & 353 & 6128 & 6768 & .855 \\
\hline & Total & 7287 & 6281 & 6665 & 6704 & 7180 & 6491 & 40608 & - \\
\hline \multirow{7}{*}{$\begin{array}{c}\text { Across all } \\
3 \text { modalities }\end{array}$} & Anger & 18189 & 349 & 2552 & 166 & 4880 & 568 & 20304 & .752 \\
\hline & Disgust & 2140 & 15727 & 555 & 307 & 937 & 638 & 20304 & .716 \\
\hline & Fear & 252 & 610 & 17640 & 119 & 571 & 1112 & 20304 & .780 \\
\hline & Happiness & 127 & 31 & 33 & 18561 & 1515 & 37 & 20304 & .864 \\
\hline & Neutral & 676 & 78 & 134 & 296 & 18652 & 467 & $20303^{*}$ & .710 \\
\hline & Sadness & 287 & 211 & 793 & 195 & 1995 & 16823 & 20304 & .709 \\
\hline & Total & 21671 & 17006 & 19707 & 19644 & 24150 & 19645 & 121823 & - \\
\hline
\end{tabular}




\section{Main analysis}

Recognition accuracy in the three modalities [Aim 1]

1 Participants' RA was significantly influenced by the modality of stimulus presentation

2 (Friedman test: $\left.\chi^{2}{ }_{(2)}=448.56, p<0.001\right)$. The results of Wilcoxon-rank-sum test indicated that

3 RA was significantly higher in the audio-visual modality than in the visual $(z=12.99, p<0.001$,

$4{ }_{95 \%} C I=[0.052 ; 0.062]$, effect size $\left.(r)=0.774\right)$ or auditory modality $(z=14.525, p<0.001$,

$595 \% C I=[0.146 ; 0.163], r=0.865)$. Participants' were also significantly more accurate at

6 discriminating emotions when making judgments on visual than on audio stimuli $(z=13.553$,

$7 p<0.001,95 \% C I=[0.090 ; 0.108], r=0.807)$. Figure 3 illustrates RA in the three conditions of

8 stimulus presentation.

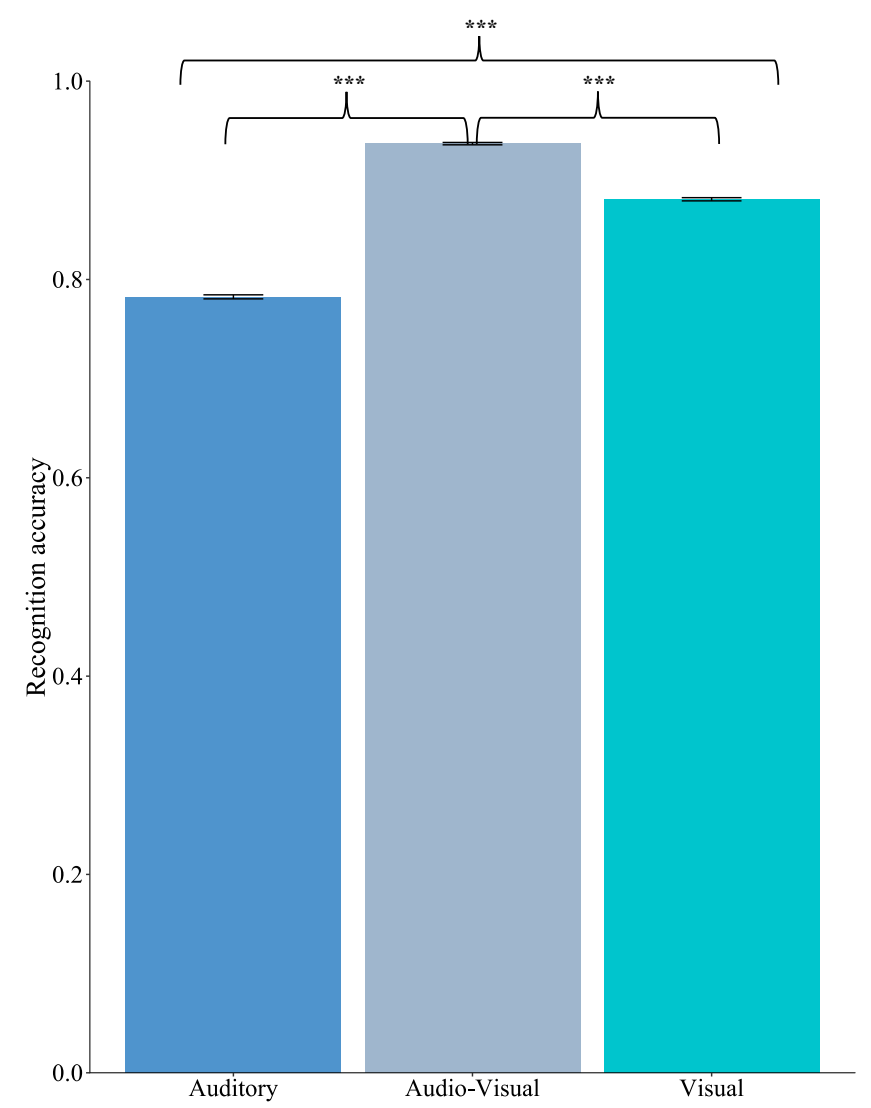

Figure 3 | Bar chart showing the recognition accuracy (RA) in the three conditions of stimulus presentation

Error bars represent the standard error. RA was significantly higher for the audiovisual presented stimuli than for the visual- or auditory stimuli. Accuracy scores were significantly higher for the visual- than for auditory condition. 


\section{Emotion specificity and modality [Aim 2]}

1 The modality of stimulus presentation across fearful, disgusted and sad expressions

2 significantly influenced participants' RA (Friedman test: $\chi^{2}{ }_{(2)}=400.47, p<0.001$ ) and RTs

3 (Friedman test: $\chi_{(2)}^{2}=208.77, p<0.001$ ). Results comparing RA and RTs between modalities

4 for each emotion category showed that participants were significantly more accurate and faster

5 at categorizing these emotions in the audio-visual than auditory modality $(p s<0.001$; effect

6 sizes for accuracy ranging from $0.813<r<0.852$ and for RTs ranging from $0.422<r<0.760$ ).

7 Although RA was significantly higher for disgust $(p<0.001 ; r=0.605)$ and sad expressions $(p$

$8<0.001 ; r=0.417)$ in the audio-visual than visual modality, the accuracy scores for fear did not

9 significantly differ between these two modalities $(p=1.00 ; r=0.038)$. Similarly, we observed no significant RT differences between the audio-visual and visual modality for these three emotions ( $p \mathrm{~s}>0.05 ; 0.005<r<0.159)$. While participants were significantly better at

12 recognizing angry expressions in the voice than in the face $(p<0.001, r=0.492)$, RTs did not

13 differ significantly between these two modalities $(p=1.00, r=0.052)$. In contrast, happy, disgusted, fearful, and sad expressions had significantly higher accuracy scores and faster RTs when they were presented visually than auditorily $\left(p \mathrm{~s}<0.001 ; 0.625<r_{\text {Accuracy }}<0.868 ; 0.487\right.$ $<r_{\mathrm{RT}}<0.816$ ). Table 3 displays the test statistics for each modality and emotion category.

\section{Interplay of hormones, recognition accuracy and reaction times [Aim 3]} coefficients $\left(r_{s}\right)$ close to zero; Figure $S 1$ in supplementary material illustrates the relationship between $\mathrm{T}$ or $\mathrm{C}$ and RA/RTs, also across all modalities). Similarly, there were no significant associations between $\mathrm{T}$ or $\mathrm{C}$ and RA/RTs for specific emotion categories (see Table $\mathrm{S} 2$ in supplementary material). Logistic and linear models, however, showed that the interaction 
Table 3 | Recognition accuracy (RA) and reaction times (RTs) standardized $z$-scores, p-values, 95\% confidence intervals (CI95\%) and effect sizes (r) for the comparisons between modalities by emotion categories

\begin{tabular}{|c|c|c|c|c|c|c|c|c|c|c|c|}
\hline \multirow{9}{*}{$\begin{array}{c}\text { Audio-visual } \\
\text { vs. } \\
\text { Visual }\end{array}$} & \multirow{4}{*}{$\begin{array}{c}\text { Emotions } \\
\text { Anger }\end{array}$} & \multicolumn{5}{|c|}{$R A$} & \multicolumn{5}{|c|}{$R T$} \\
\hline & & \multirow[t]{2}{*}{$z$} & \multirow[t]{2}{*}{$p$} & \multicolumn{2}{|c|}{ CI95\% } & \multirow[t]{2}{*}{$r$} & \multirow[t]{2}{*}{$z$} & \multirow[t]{2}{*}{$p$} & \multicolumn{2}{|c|}{ CI95\% } & \multirow[t]{2}{*}{$r$} \\
\hline & & & & $\mathrm{LL}$ & UL & & & & LL & UL & \\
\hline & & 13.71 & $<0.001$ & 0.125 & 0.146 & 0.816 & -8.645 & $<0.001$ & -0.299 & -0.200 & 0.515 \\
\hline & Disgust & 10.155 & $<0.001$ & 0.104 & 0.125 & 0.605 & 0.550 & 1.00 & -0.032 & 0.569 & 0.033 \\
\hline & Fear & 0.632 & 1.00 & -0.000 & 0.021 & 0.038 & 2.677 & 0.134 & 0.019 & 0.126 & 0.159 \\
\hline & Happiness & -2.820 & 0.087 & -0.041 & -0.000 & 0.168 & 3.397 & 0.012 & 0.018 & 0.072 & 0.202 \\
\hline & Sadness & 6.995 & $<0.001$ & 0.042 & 0.083 & 0.417 & 0.089 & 1.00 & -0.044 & 0.051 & 0.005 \\
\hline & Neutral & 9.547 & $<0.001$ & 0.062 & 0.083 & 0.568 & 1.978 & 0.864 & 0.000 & 0.079 & 0.118 \\
\hline \multirow{6}{*}{$\begin{array}{c}\text { Audio-visual } \\
\text { vs. } \\
\text { Auditory }\end{array}$} & Anger & 10.579 & $<0.001$ & 0.063 & 0.083 & 0.630 & -6.736 & $<0.001$ & -0.302 & $\begin{array}{c}-0.170 \\
\end{array}$ & 0.401 \\
\hline & Disgust & 14.315 & $<0.001$ & 0.250 & 0.271 & 0.852 & -12.765 & $<0.001$ & -0.735 & -0.562 & 0.760 \\
\hline & Fear & 13.646 & $<0.001$ & 0.167 & 0.188 & 0.813 & -9.653 & $<0.001$ & -0.526 & -0.366 & 0.575 \\
\hline & Happiness & 14.534 & $<0.001$ & 0.188 & 0.208 & 0.865 & -11.709 & $<0.001$ & -0.506 & -0.373 & 0.697 \\
\hline & Sadness & 13.858 & $<0.001$ & 0.187 & 0.208 & 0.825 & -7.087 & $<0.001$ & -0.359 & -0.208 & 0.422 \\
\hline & Neutral & 8.789 & $<0.001$ & 0.062 & 0.083 & 0.523 & -8.659 & $<0.001$ & -0384 & -0.242 & 0.516 \\
\hline \multirow{6}{*}{$\begin{array}{c}\text { Auditory } \\
\text { vs. } \\
\text { Visual }\end{array}$} & Anger & 8.268 & $<0.001$ & 0.063 & 0.104 & 0.492 & -0.865 & 1.00 & $2-0.094$ & 0.036 & 0.052 \\
\hline & Disgust & -10.50 & $<0.001$ & -0.187 & -0.146 & 0.625 & 13.711 & $<0.001$ & 0.597 & 0.746 & 0.816 \\
\hline & Fear & -13.318 & $<0.001$ & -0.188 & -0.167 & 0.793 & 12.113 & $<0.001$ & 0.433 & 0.579 & 0.721 \\
\hline & Happiness & -14.574 & $<0.001$ & -0.229 & -0.188 & 0.868 & 13.51 & $<0.001$ & 0.443 & 0.571 & 0.805 \\
\hline & Sadness & -11.603 & $<0.001$ & -0.187 & -0.146 & 0.691 & 8.179 & $<0.001$ & 0.232 & 0.370 & 0.487 \\
\hline & Neutral & 0.941 & 1.00 & -0.000 & 0.021 & 0.056 & 10.323 & $<0.001$ & 0.295 & 0.420 & 0.615 \\
\hline
\end{tabular}

Note: The differences in RA and RT between modalities by emotion categories were analyzed using Wilcoxon-rank-sum test. All p-values for RA and RT were for 18 comparisons ( 3 modalities * 6 emotions) Bonferroni corrected. Positive $z$-scores indicate that RA is higher and RTs longer for the first vs. second modality, whereas negative z-scores indicate that RA is lower and RTs shorter for the first vs. second modality.

$1 p<0.001, r=0.022)$ and RTs $\left(F_{(4,121806)}=8.26, p<0.001, r=0.016\right)$. Table $S 3$ in

2 supplementary material provides an overview on the model terms and the corresponding

3 statistics for both RA and RTs. The odds ratio estimates for RA and the linear contrasts for the

4 pattern of the differences in RTs for all combinations between $\mathrm{T}$ and $\mathrm{C}$ terciles showed that

5 participants RA was significantly higher for $T_{H i g h} / C_{L o w}$ and $T_{L o w} / C_{H i g h}$, but lower for $T_{\text {Middle }} / C_{\text {Low }}$

6 or $T_{\text {Low }} / C_{\text {Middle. }}$ RTs were shorter for $T_{H i g h} / C_{\text {Low }}, T_{\text {Low }} / C_{\text {Low }}$, as well as for $T_{\text {Low }} / C_{\text {Middle. }}$ For the

7 combinations $T_{\text {High }} / C_{H i g h}$ or $T_{\text {Middle }} / C_{\text {High }}$ RTs were significantly longer. In Figure 4, panels A,

8 B display the corresponding statistics for all comparisons between $\mathrm{T}$ and $\mathrm{C}$ terciles, while panels

$9 \quad \mathbf{A}_{\mathbf{I}}, \mathbf{B}_{\mathbf{I}}$ illustrate the conditional patterns.

\section{Discussion}

10 The main objective of the present study was to investigate whether males' RA is influenced by

11 the modality of stimulus presentation in an explicit emotion recognition task. In addition, we

12 examined whether specific emotions are more quickly and accurately detected as a function of

13 modality. Finally, we explored the effects of individual differences in $\mathrm{T}$ and $\mathrm{C}$, as well as their

14 interaction with RA and RTs. Our results provide compelling evidence that RA is greatly

15 improved when visual and audio information were jointly presented and that happy expressions 
(A)

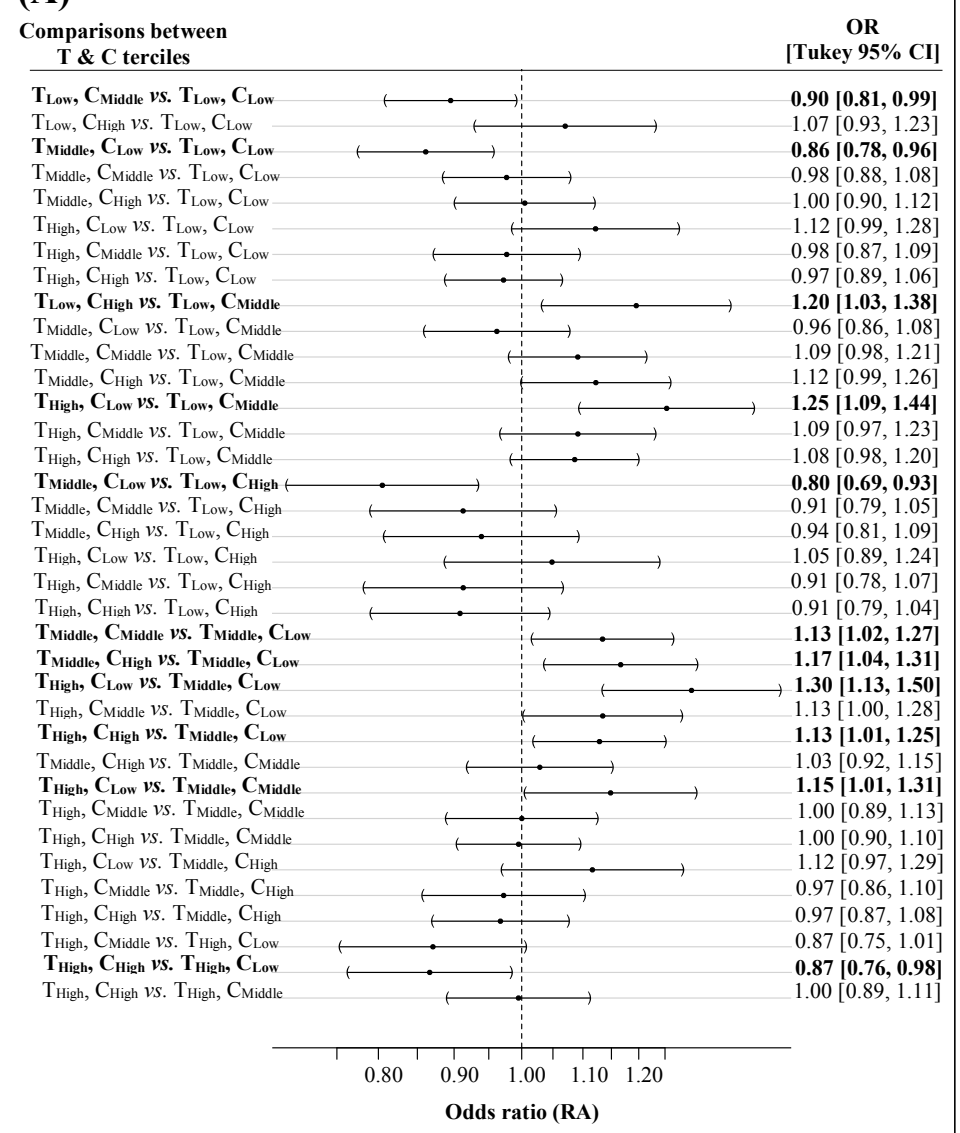

(A)
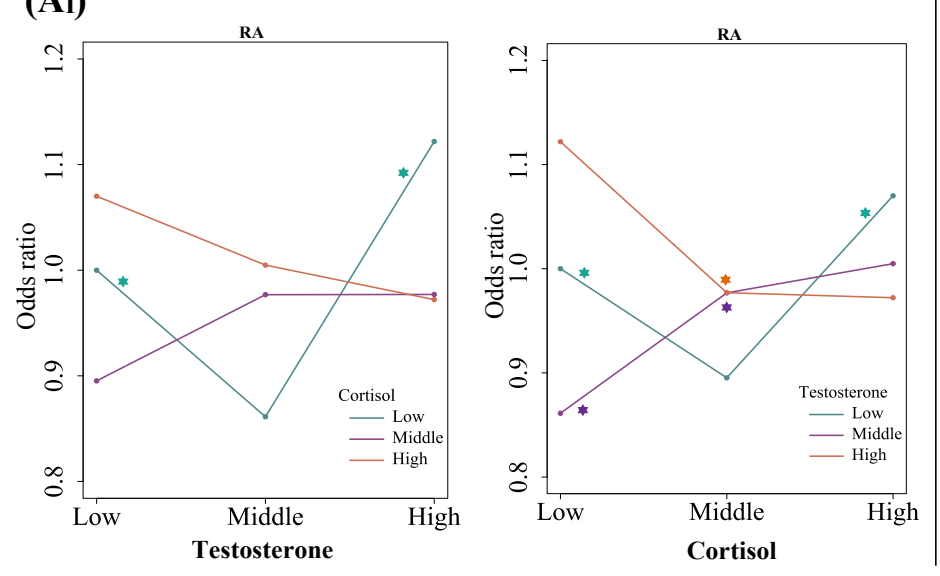

(B)

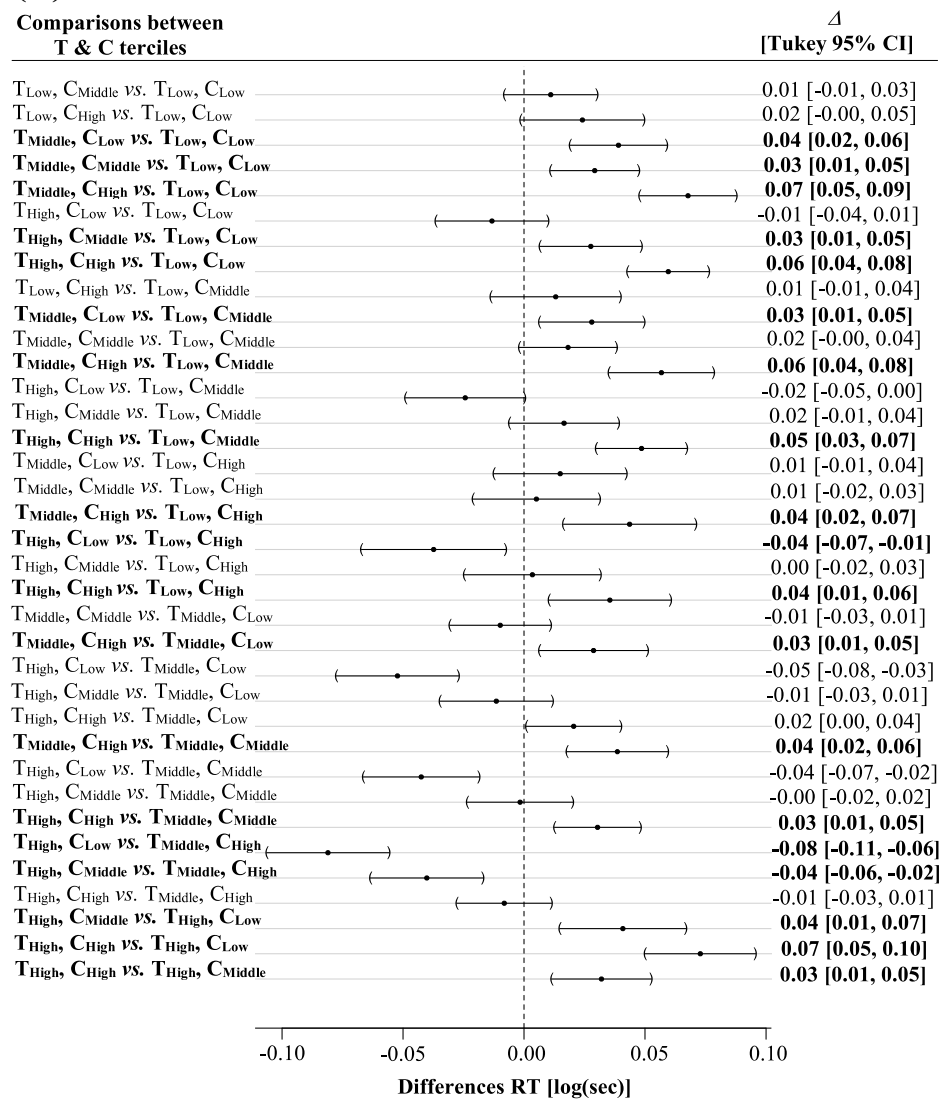

(B ${ })$
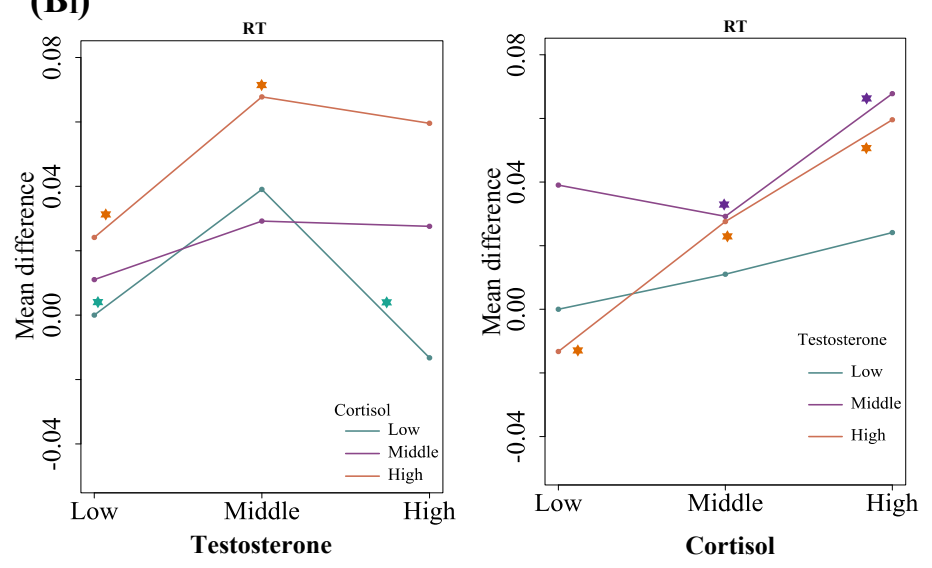

* middle $=$ the comparison between low and high is significant

* left side $=$ the comparison between low and middle is significant

* right side $=$ the comparison between middle and high is significant

Figure 4 | Pairwise comparisons and conditional patterns of $\mathrm{T}$ and $\mathrm{C}$ terciles combinations for recognition accuracy (RA) and reaction time $(\mathrm{RT})$

The comparisons between hormone terciles for RA are illustrated in panel (A), while the linear contrasts for the pattern of the differences in RT are illustrated in panel (B). The significant combinations are highlighted in bold. The T pattern conditional under $\mathrm{C}$ and $\mathrm{C}$ pattern conditional under T for RA are shown in panel $\left(\mathbf{A}_{\mathbf{I}}\right)$ and panel $\left(\mathbf{B}_{\mathbf{I}}\right)$ for $\mathrm{RT}$.

In panel (A) odds ratio for combination 1 (e.g., $T_{H i g h} / C_{H i g h}$ ) vs. combination 2 (e.g., $T_{H i g h} / C_{\text {Low }}$ ) less than 1 indicate that the recognition probability for combination $2\left(T_{H i g h} / C_{L o w}\right)$ is higher than for combination $1\left(T_{H i g h} / C_{H i g h}\right)$, whereas values greater than 1 vice-versa. If the odds ratio of 1 is included in the confidence interval, the difference in the recognition probabilities is not significant. In panel (B) negative differences of RT for combination 1 (e.g., $\left.T_{H i g h} / C_{H i g h}\right)$ vs. combination 2 (e.g., $T_{H i g h} / C_{L o w}$ ) indicate that the RT for combination $2\left(T_{H i g h} / C_{H i g h}\right)$ are longer than for combination $1\left(T_{H i g h} / C_{L o w}\right)$, whereas positive differences vice-versa. If the difference of zero is included in the $95 \% \mathrm{CI}$, the difference in RT is not significant.

As it can be observed, for $\boldsymbol{T}$ conditional under $\boldsymbol{C}_{\boldsymbol{L} \text { ow }}$ and $\boldsymbol{C}$ conditional $\boldsymbol{u n d e r} \boldsymbol{T}_{\boldsymbol{L} o w}$ there is a quadratic relationship [i.e., the accuracy decreases from low to middle $\mathrm{T}$ or $\mathrm{C}$ and then increases from middle to high $\mathrm{T}$ or $\mathrm{C}$ (see panel $\mathrm{A}_{\mathrm{I}}$ ); for $\boldsymbol{T}$ conditional under $\boldsymbol{C}_{\boldsymbol{L} \text { ow }}$ the RT increases from low to middle $\mathrm{T}$ and then decreases from middle to high $\mathrm{T}$ (see panel $\mathrm{B}_{\mathrm{I}}$ )]. For $\boldsymbol{C}$ conditional under $\boldsymbol{T}_{\boldsymbol{H} \text { igh }}$ the relationship is monotone [i.e., the accuracy decreases from low $\mathrm{C}$ to high $\mathrm{C}$ ( see panel $\mathrm{A}_{\mathrm{I}}$ ); the $\mathrm{RT}$ increases from low $\mathrm{C}$ to high $\mathrm{C}$ $\left(\right.$ see panel $\left.\mathrm{B}_{\mathrm{I}}\right)$ ]. 
1 were identified faster and with higher accuracy from faces than voices. Conversely, angry

2 expressions were better recognized from voices than faces. Although no significant associations

3 between single hormones (i.e., T or C) and RA or RTs were found, results showed that TxC

4 interaction was significantly associated with both RA and RTs.

5 Our data highlights that the audio-visual presentation of emotional expressions significantly

6 contributes to the ease and efficiency with which others' emotions are recognized. This is in

7 line with previous studies showing that the integration of auditorily and visually presented

8 emotional information facilitates emotion recognition [e.g., Jessen et al., 2012; Paulmann \&

9 Pell, 2011; Baenziger et al., 2009), reflected in higher accuracy and faster RTs, especially for

10 emotions such as disgust, fear (Collignon et al., 2008) and sadness (Kreifelts et al., 2007). One

11 of the most noticeable differences between the present study and previous investigations was

12 the presentation of several emotions and a neutral category (e.g., Collignon et al., 2008; De

13 Gelder \& Vroomen, 2000, included only two emotions) and the measurement of RTs (e.g., not

14 considered in Kreifelts et al., 2007 study). Yet, the facilitation effect concerning stimulus

15 classification manifested for every single emotion category during the audio-visual modality in

16 comparison to the auditory modality. In addition, RA in the audio-visual modality exceeded

17 that of the visual modality for angry, disgusted, neutral and sad emotions, which indicates the comprehensive nature of this integration process. As shown by the present results there are some differences in the effectiveness, with which specific emotions are recognized from voices and faces. Similar to the results reported in a meta-analysis by Elfenbein and Ambady (2002), anger was recognized better from voice than faces in our study, while better results for

22 happiness were achieved from the visual compared to the auditory modality. This suggests that sensory modalities do not merely carry redundant information but rather, each may have certain specialized functions for the communication of emotions. Although the estimation of a visual 
1 that the louder, higher pitched sound of anger is particularly useful for both, proximal and distal

2 spaces (see Ceravolo et al., 2016, for details). As it is highly adaptive to recognize and react to

3 a potential threat in the environment (Pichon et al., 2008), the accurate detection of anger might,

4 therefore, rely more on the human auditory than visual system. Previous research on facial

5 expression recognition has consistently reported that happy expressions are recognized more

6 accurately and faster than other basic emotions (e.g., Nummenmaa \& Calvo, 2015). Our data

7 provide further support for these findings, but not for our prediction (1b) that emotions

8 communicated by the voice are recognized at higher rates of accuracy than in the visual channel.

9 Nevertheless, it is possible that what determines the recognition advantage of happy faces is

10 not so much their affect, but rather their perceptual and categorical distinctiveness from other

11 emotional expressions (see Calvo et al., 2014, for details) as well as their frequent occurrence

12 in everyday social contexts, thus, tuning the visual system towards efficient recognition of these

13 faces (Nummenmaa \& Calvo, 2015). Moreover, it has been argued that physical feature

14 extraction can occur instantaneously for facial expressions, while the interplay of acoustic cues

15 over time occurs in a probabilistic manner (Juslin \& Laukka, 2003) and thus, may not engage

16 a similar process for vocal expressions (see Paulmann \& Pell, 2011, for details). This could

17 have strengthened the underlying knowledge about emotions leading to improved RA and RTs

18 in the visual modality.

19 The available evidence regarding the relationship between $\mathrm{T}$ and males' emotion recognition 20 ability is by no means clear-cut, making explicit claims about the direction of these effects 21 impossible. The two predictions made in the present study were based on reported observations 22 that $\mathrm{T}$ might have a negative influence on the recognition of emotions (Rukavina et al., 2018;

23 Fujisawa \& Shinohara, 2011), and that RTs of threat-related emotional expressions (i.e., angry, 24 fear) would be much shorter with increasing levels of T (Derntl et al., 2009). To provide a more 25 detailed picture of this association, we conducted an exploratory analysis for each modality and 
1 emotion category separately. In a similar fashion, we additionally analysed the effects of C.

2 Similar to other reports in the literature, our data do not provide support for the influence of

3 single steroid hormones (i.e., T or C) on RA or RTs (Duesenberg et al., 2016; Derntl et al.,

4 2009). In contrast to the reported effect sizes or the significant effects between $T$ and specific

5 emotion categories (Rukavina et al., 2018; Derntl et al., 2009), the correlation coefficients for

6 both hormones were small or close to zero across all modalities in our study. Despite our

7 comparatively large sample, single hormones (i.e., T, C) did not appear to have an impact on

$8 \quad$ RA and RTs in explicit emotion recognition tasks.

9 One assumption that has been put forth is that $\mathrm{T}$ and $\mathrm{C}$ do not act in isolation but rather interact

10 to modulate complex social behaviours (Carré \& Mehta, 2011). Following the dual-hormone

11 hypothesis (Mehta \& Josephs, 2010), we further explored whether the relationship between T and our response variables (i.e., RA and RT) is enhanced when C levels are low and attenuated when C levels are high. Similar to the obtained results in Dekkers et al. meta-analysis (2019) the overall effect size of $\mathrm{T}$ by cortisol interaction on RA and RT was significant but small in our study. Although our data support the dual-hormone hypothesis to some extent, they also showed that the interplay between $\mathrm{T}$ and $\mathrm{C}$ with RA or RTs is not as straightforward as one would expect. For instance, accuracy increased and RTs were shorter not only when T was high and $\mathrm{C}$ was low or vice-versa, but also when $\mathrm{T}$ and $\mathrm{C}$ were low. As our study is the first to account for the interaction between $\mathrm{T}$ and $\mathrm{C}$ on $\mathrm{RA}$ or $\mathrm{RT}$, we cannot clearly provide explanations that might account for the observed mixed-pattern of results. However, as previous research found that high T and stress (C) levels impair cognitive abilities (e.g., Haenggi, 2004;

22 Gouchie \& Kimura, 1991) and decrease performance [e.g., Dolcos et al., 2014; Mehta et al., 2009), one would expect that with low levels of T and C, or with optimal levels of stress (i.e., eustress) but low T levels RA would increase in cognitive tasks. Since the pattern of the TxC interaction we found is unexpected and the effect size is small, we cannot rule out that it is a 
1 false-positive finding. Certainly, more work is needed to replicate our findings and to test these 2 claims.

3 While our knowledge of how emotional information is integrated and recognized across 4 channels is advancing steadily, the available literature, including the present study, is limited 5 in a number of ways. In comparison to our study, most of the research mentioned above has 6 evaluated a very small number of emotions (sometimes as few as two) and did not include a 7 neutral baseline. Further, in some studies the audio material consisted of speech prosody 8 (words, sentences). This opens up the possibility that the emotional tone of voice interacted 9 with the affective value carried by the sentence's/word's semantic content. A related issue of 10 past work is the use of emotional exemplars in conflict situations argued to be highly atypical 11 of natural expressions of emotions (Paulmann \& Pell, 2011). We addressed these issues by presenting emotion stimuli devoid of meaning (i.e., pseudo-words, pseudo-sentences and affect bursts) which always contained a congruent set of cues (i.e., encoder sex, stimulus time length) to express one of five basic emotions or a neutral state. We chose static faces to ensure our experimental conditions of stimulus presentation were compatible with the majority of prior literature. However, this format has been argued to be less ecologically valid (Krumhuber et al., 2013; Recio et al., 2011). While this assumption is still subject to some controversy (see Dobs et al., 2018, for details), future studies would benefit from using datasets of more naturalistic stimuli to further increase ecological validity.

As most of the previous research has focused on the associations between single hormones and

21 facial emotion recognition, the present study uniquely contributes to the literature by providing a systematic examination of the influence of $\mathrm{T}, \mathrm{C}$ and their interaction on RA and RT across different sensory modalities (i.e., auditory, visual and audio-visual). Although for C as well as

24 for the interaction between $\mathrm{T}$ and $\mathrm{C}$, the analyses were exploratory, they might prove of 25 importance for researchers conducting work in this area to gain a more comprehensive 
1 understanding of when these effects emerge and when they do not. They may also yield a

2 substantial theoretical payoff by enabling richer and more accurate predictions concerning the

3 kind of outcomes tied to certain hormone level combinations.

4 The homogeneous characteristics of our sample (i.e., university students, narrow age range)

5 may show patterns which do not hold for different sociodemographic subgroups. Given the

6 increased focus on study replicability, future studies would benefit from combining datasets of

7 different laboratories with similar outcome measures in order to reduce costs and increase the

8 external validity, reliability and generalizability of findings. The present study provided

9 evidence for differences in both RA and RTs in the three conditions of stimulus presentation

10 and potentially set the stage regarding the influence of $\mathrm{TxC}$ interaction on these two response

11 variables. It would thus be worthwhile to expand on these findings and examine whether the

12 same holds true for the other sex. This could be done, for instance, by investigating the

13 interaction between oestradiol and cortisol with RA, as previous research showed that high

14 oestradiol is associated with more externalizing behaviours (linked to emotion-recognition

15 difficulties, see Chronaki et al., 2015), but only when cortisol was low (Tackett et al., 2015).

\section{Conclusion}

The findings of this study inform our current understanding with regard to the audio-visual

17 integration of emotional signals among men by showing that audio-visual stimuli benefit RA over unimodal stimuli. They also explain inconsistencies in the past literature by highlighting that in explicit emotion recognition tasks voice-only expressions do not increase RA. Moreover,

20 they replicate previous findings by establishing that for particular emotion categories RA and 21 RTs vary as a function of modality. Crucially, our study contributes to a scientific domain that is currently reconsidering our understanding of the role hormones play for the recognition of emotions. It hereby paves the way for impactful future research, especially for the effects

24 regarding $\mathrm{TxC}$ interaction with $\mathrm{RA}$ and $\mathrm{RT}$. 


\section{Acknowledgments}

1 The authors thank Edmund Henniges for technical support, Saskia Brueckner, Marc Koehler

2 and Isabel Noethen for help with data acquisition and all individuals who participated in the

3 research presented here.

\section{Author contributions}

4 A. L. designed the research with input from C. B., L. P. and A.S.; C. B. collected part of the 5 data and wrote on the method part; A.L. analysed the data and wrote the paper with input from 6 C. B., L. P. and A.S.

\section{Funding}

7 This research was funded by Leibniz ScienceCampus "Primate Cognition"- Project number

86900199 Leibniz-WissenschaftsCampus and Deutsche Forschungsgemeinschaft (DFG,

9 German Research Foundation) - Project number 254142454/GRK 2070.

\section{Competing Interests}

10 The authors declare no competing interests.

\section{Data availability}

11 The dataset generated and analysed for the current study is available at osf.io/2ayms.

\section{References}

12 Banse, R., Scherer, K. R., 1996. Acoustic profiles in vocal emotion expression. J. Pers. Soc.

13 Psychol. 70, 614-636. http://dx.doi.org/10.1037/0022-3514.70.3.614

14 Belin, P., Fillion-Bilodeau, S., Gosselin, F., 2008. The Montreal affective voices: a validated 15 set of nonverbal affect bursts for research on auditory affective processing. Behav. Res. 16 Methods 40, 531-539. http://dx.doi.org/10.3758/BRM.40.2.531

17 Baenziger, T., Grandjean, D., Scherer, K., 2009. Emotion recognition from expressions in face, 18 voice, and body: the multimodal emotion recognition test (MERT). Emotion 9, 691-704. 19 https://doi.org/10.1037/a0017088

20 Breyer, B. Bluemke, M., 2016. Deutsche Version der Positive and Negative Affect Schedule 21 PANAS (GESIS panel), in: Zusammenstellung Sozialwissenschaftlicher Items und Skalen. 22 https://doi.org/10.6102/zis242 
1 Calvo, M. G., García, A. G., Martín, A. F., Nummenmaa, L., 2014. Recognition of facial 2 expressions of emotion is related to their frequency in everyday life. J. Nonverbal Behav. 38, 3 549-597. https://doi.org/10.1007/s10919-014-0191-3

4 Carré, J.M., Mehta, P. H., 2011. Importance of considering testosterone-cortisol interactions in 5 predicting human aggression and dominance. Aggress. Behav. 37, 489-491.

6 https://doi.org/10.1002/ab.20407

7 Ceravolo, L., Frühholz, S., Grandjean, D., 2016. Proximal vocal threat recruits the right voice8 sensitive auditory cortex. Soc. Cogn. Affect. Neurosci. 11, 793-802.

9 https://doi.org/10.1093/scan/nsw004

10 Chaplin, T. M., 2015. Gender and emotion expression: a developmental contextual perspective. 11 Emot. Rev. 7, 14-21. https://doi.org/10.1177/1754073914544408 cultural recognition of vocal emotions during childhood and adolescence. Sci. Rep. 8, 8659. https://doi.org/10.1038/s41598-018-26889-1

Chronaki, G., Garner, M., Hadwin, J.A., Thompson, M. J. J., Chin, C. Y., Sonuga-Barke, E. J. S., 2013. Emotion-recognition abilities and behavior problem dimensions in preschoolers: evidence for a specific role for childhood hyperactivity. Child Neuropsychol. 21, 25-40. https://doi.org/10.1080/09297049.2013.863273

Collignon, O., Girard, S., Gosselin, F., Roy, S., Saint-Amour, D., Lassonde, M., Lepore, F., 2008. Audio-visual integration of emotion expression. Brain Res. 1242, 126-135. https://doi.org/10.1016/j.brainres.2008.04.023

Cornew, L., Carver, L., Love, T., 2009. There's more to emotion than meets the eye: a processing bias for neutral content in the domain of emotional prosody. Cogn. Emot. 24, 11331152. https://doi.org/10.1080/02699930903247492

Danner, D. et al. (2016). Die deutsche version des Big Five Inventory 2 (BFI-2), in Zusammenstellung sozialwissenschaftlicher items und skalen. https://doi.org/10.6102/zis247

Dekkers, T. J., Agelink van Rentergem, J. A., Meijera, B., Popmab, A., Wagemakera, E., Huizengaa, H. M., 2019. A meta-analytical evaluation of the dual-hormone hypothesis: does cortisol moderate the relationship between testosterone and status, dominance, risk taking, aggression, and psychopathy? Neurosci. Biobehav. Rev. 96, 250-271.

31 https://doi.org/10.1016/j.neubiorev.2018.12.004

Derntl, B., Windischberger, C., Robinson, S., Kryspin-Exner, I., Gur, R. C., Moser, E., Habel, U., 2009. Amygdala activity to fear and anger in healthy young males is associated with testosterone. Psychoneuroendocrinology 34, 687-693.

35 https://doi.org/10.1016/j.psyneuen.2008.11.007

Dobs, K., Bülthoff, I., Schultz, J., 2018. Use and usefulness of dynamic face stimuli for face perception studies - a review of behavioral findings and methodology. Front. Psychol. 9, 1355. https://doi.org/10.3389/fpsyg.2018.01355 
1 Dolcos, F., Wang, L, Mather, M. 2014. Current research and emerging directions in emotion2 cognition interactions. Front. Integr. Neurosci. 8, 83. https://doi.org/10.3389/fnint.2014.00083

3 Duesenberg, M., Weber, J., Schulze, L., Schaeuffele, C., Roepke, S., Regen, J. H., Otte, C., 4 Wingenfeld, K., 2016. Does cortisol modulate emotion recognition and empathy? 5 Psychoneuroendocrinology 66, 221-227. https://doi.org/10.1016/j.psyneuen.2016.01.011

6 Dziobek, I., Rogers, K., Fleck, S., Bahnemann, M., Heekeren, H. R., Wolf, O. T., Convit, A., 7 2008. Dissociation of cognitive and emotional empathy in adults with Asperger syndrome using 8 the multifaceted empathy test (MET). J. Autism Dev. Disord. 38, 464-473. 9 https://doi.org/10.1007/s10803-007-0486-x

10 de Gelder, B., Vroomen, J. 2000. The perception of emotions by ear and by eye. Cogn. Emot. 11 14, 289-311. https://doi.org/10.1080/026999300378824

Elfenbein, H. A., Ambady, N. 2002. On the universality and cultural specificity of emotion recognition: a meta-analysis. Psychol. Bull. 128, 203-235. https://doi.org/10.1037/0033$\underline{2909.128 .2 .203}$

Fischer, A. H., LaFrance, M. 2015. What drives the smile and the tear: why women are more

Emot.

Rev.

7, 22-29.

Fischer, A. H., Manstead, A. S. R., 2008. Social functions of emotion, in Lewis, M., HavilandJones, J., Barrett L. F. (Eds.), Handbook of emotions ( $3^{\text {rd }}$ Ed). Guilford Press, New York, pp. $456-468$.

Fujisawa, T. X., Shinohara, K., 2011. Sex differences in the recognition of emotional prosody in late childhood and adolescence. J. Physiol. Sci. 61, 429-435. https://doi.org/10.1007/s12576$\underline{011-0156-9}$

Gignell, M., Hornung, J., Derntl, B., 2019. Emotional processing and sex hormones, in Schultheiss O. C., Mehta P. H. (Eds.), Routledge International Handbook of Social Neuroendocrinology ( $1^{\text {st }} \quad$ Ed.). Routledge, Abingdon, UK, pp. 403-419. https://www.routledgehandbooks.com/doi/10.4324/9781315200439-24

Gouchie, C., Kimura, D., 1991. The relationship between testosterone levels and cognitive ability patterns. Psychoneuroendocrinology, 16, 323-334. https://doi.org/10.1016/0306$30 \quad \underline{4530(91) 90018-\mathrm{O}}$

31 Grebe, N.M., Del Giudice, M., Thompson, M.E., Nickels, N., Ponzi, D., Zilioli, S., Mastripieri, 32 D., Gangestad, S.W., 2019. Testosterone, Cortisol, and Status-Striving Personality Features: A 33 Review and Empirical Evaluation of the Dual Hormone Hypothesis. Horm. Behav. 109, 25-37. 34 https://doi.org/10.1016/j.yhbeh.2019.01.006 
1 Hall, J. A., 1984. Non-Verbal Sex Differences. Communication Accuracy and Expressive Style.

2 John Hopkins Press, London.

3 Haenggi Y., 2004. Stress and Emotion Recognition: An Internet Experiment Using Stress

4 Induction. Swiss Journal of Psychology 63, 113-125. https://doi.org/10.1024/1421-

$5 \quad \underline{0185.63 .2 .113}$

6 Hyde, J. S., 2014. Gender similarities and differences. Annu. Rev. Psychol. 65, 373-398.

7 https://doi.org/10.1146/annurev-psych-010213-115057

8 Jessen, S., Obleser, J., Kotz, S. A., 2012. How bodies and voices interact in early emotion

9 perception. PLoS ONE 7, e36070. http://dx.doi.org/10.1371/journal.pone.0036070

Juslin, P. N., Laukka, P., 2003. Communication of emotions in vocal expression and music performance: different channels, same code? Psychol. Bull. 129, 770-814. http://dx.doi.org/10.1037/0033-2909.129.5.770

Keltner, D., Kring, A.M., 1998. Emotion, social function and psychopathology. Rev. General Psychol. 2, 320-342. http://dx.doi.org/10.1037/1089-2680.2.3.320

Klasen, M., Kreifelts, B., Chen, Y. H., Seubert, J., Mathiak, K., 2014. Neural processing of emotion in multimodal settings. Front. Hum. Neurosci. $8, \quad 822$ http://dx.doi.org/10.3389/fnhum.2014.00822

Kordsmeyer, T. L., Lohöfener, M., Penke, L., 2018. Male facial attractiveness, dominance, and health and the interaction between cortisol and testosterone. Adapt. Human Behav. Physiol., 112. https://doi.org/10.1007/s40750-018-0098-z

Kosonognov, V., Titova, A., 2018. Recognition of all basic emotions varies in accuracy and reaction time: A new verbal method of measurement. Int. J. Psychol. 16, http://dx.doi.org/10.1002/ijop.12512 expressions: a review. Emot. Rev. 5, 41-46. http://dx.doi.org/10.1177/1754073912451349

Lambrecht, L., Kreifelts, B., Wildgruber, D (2014). Gender differences in emotion recognition: impact of sensory modality and emotional category. Cogn. Emot. 28, 452-469. http://dx.doi.org/10.1080/02699931.2013.837378

29 Langner, O., Dotsch, R., Bijlstra, G., Wigboldus, D. H. J., Hawk, S. T., van Knippenberg, Ad, 30 2010. Presentation and validation of the Radboud Faces Database. Cogn. Emot. 24, 1377-1388. 31 http://dx.doi.org/10.1080/02699930903485076 1456. https://doi.org/10.1016/j.neuroimage.2007.06.020. 
1 Lausen, A., Hammerschmidt, K., Schacht, A., 2019. Emotion recognition and confidence 2 ratings predicted by vocal stimulus type and acoustic parameters. 3 https://doi.org/10.31234/osf.io/kqy2n

4 Lausen, A., Schacht, A., 2018. Gender differences in the recognition of vocal emotions. Front.

5 Psychol. 9, 882. https://doi.org/10.3389/fpsyg.2018.00882

6 Mazur, A., Booth, A., 2014. Testosterone is related to deviance in male army veterans, but 7 relationships are not moderated by cortisol. Biol. Psychol. 96, 72-76. 8 https://doi.org/10.1016/j.biopsycho.2013.11.015

9 Mehta, P.H., Prasad, S., 2015. The dual-hormone hypothesis: A brief review and future research 10 agenda. Curr. Opin. Behav. Sci. 3, 163-168. https://doi.org/10.1016/j.cobeha.2015.04.008

Mehta, P.H., Josephs, R.A., 2010. Testosterone and cortisol jointly regulate dominance: Evidence for a dual-hormone hypothesis. Horm. Behav. 58, 898-906. https://doi.org/10.1016/j.yhbeh.2010.08.020

Mehta, P.H., Wuehrmann, E.V. Josephs R. A. 2009. When are low testosterone levels advantageous? The moderating role of individual versus intergroup competition. Horm. Behav. 56, 158-162. https://doi.org/10.1016/j.yhbeh.2009.04.001

Montagne, B., Kessels, R. P., de Haan, E. H. F., Perrett, D. I., 2007. The emotion recognition task: a paradigm to measure the perception of facial emotional expressions at different intensities. Percept. Mot. Skills 104, 589-598. https://doi.org/10.2466/pms.104.2.589-598

Nummenmaa, L., Calvo, M. G., 2015. Dissociation between recognition and detection advantage for facial expressions: a meta-analysis. Emotion 15, 243-256. http://dx.doi.org/10.1037/emo0000042

Palermo, R. Coltheart, M., 2004. Photographs of facial expression: accuracy, response times, and ratings of intensity. Behav. Res. Methods Instrum. Comput. 36, 634-638. https://doi.org/10.3758/BF03206544 69. http://dx.doi.org/10.1016/j.bandl.2007.11.005

Paulmann, S., Pell, M.D., Kotz, S.A., 2008. How aging affects the recognition of emotional speech, Brain Lang. 104, 262-269. http://dx.doi.org/10.1016/j.bandl.2007.03.002 decoding of emotion from human non-linguistic vocalizations versus speech prosody. Biol. Psychol. 111, 14-25. http://doi.org/10.1016/j.biopsycho.2015.08.008

Pichon, S., de Gelder, B., Grèzes, J., 2008. Emotional modulation of visual and motor areas by dynamic body expressions of anger. Soc. Neurosci. 3, 199-212. 
1 Piwek, L., Pollick, F., Petrini, K., 2015. Audiovisual integration of emotional signals from 2 others' social interactions. Front. Psychol. 6, 611. http://dx.doi.org/10.3389/fpsyg.2015.00611

3 R Core Team, 2017. R: A Language and Environment for Statistical Computing. Vienna: R

4 Foundation for Statistical Computing. Available online at: https:// www.r-project.org

5 Recio, G., Sommer, W., Schacht, A., 2011. Electrophysiological correlates of perceiving and 6 evaluating static and dynamic facial emotional expressions. Brain Res. 1376, 66-75. 7 https://doi.org/10.1016/j.brainres.2010.12.041

8 Rukavina, S., Sachsenweger, F., Jerg-Bretzke, L., Daucher, A. E., Traue, H. C., Walter, S., 9 Hoffmann, H., 2018. Testosterone and its influence on emotion recognition in young, healthy 10 males. Psychology 9, 1814-1827. http://dx.doi.org/10.4236/psych.2018.97106

Sarkar, A., Mehta, P. H., Josephs, R. A., 2019. The dual-hormone approach to dominance and status-seeking, in: Schultheiss O. C., Mehta P. H. (Eds.), Routledge International Handbook of Social Neuroendocrinology ( ${ }^{\text {st }}$ Ed.), Routledge, Abingdon, UK, pp. 113-132. https://www.routledgehandbooks.com/doi/10.4324/9781315200439-8

Schirmer, A., 2013. Sex differences in emotion, in: Armony, J., Vuilleumier, P. (Eds.), The 16 Cambridge Handbook of Human Affective Neuroscience ( $\left(1^{\text {st }}\right.$ Ed.). Cambridge University Press, 17 New York, pp. 591-611.

Schultheiss, O. C., Dlugash, G., Mehta, P. H., 2019. Hormone measurement in social neuroendocrinology: a comparison of immunoassay and mass spectrometry methods, in: Schultheiss O. C., Mehta P. H. (Eds.), Routledge International Handbook of Social

Neuroendocrinology ( $1^{\text {st }}$ Ed.), Routledge, Abingdon, UK, pp. 26-41. https://www.routledgehandbooks.com/doi/10.4324/9781315200439-3

Schultheiss, O. C., Schiepe, A., Rawolle, M., 2012. Hormone assays, in: Cooper, H., Camic, P. M., Long, D. L., Panter, A. T., Rindskopf, D., Sher, K. J. (Eds.), Handbook of research methods in psychology (Vol. 1), American Psychological Association, Washington, pp. 489-500.

Schultheiss, O. C., Stanton, S. J., 2009, in: Harmon-Jones, E. \& Beer, J. S. (Eds.), Methods in social neuroscience, Guilford Press: New York, pp. 17-44.

Sokolowski, K., Schmalt, H. D., Langens, T. A., Puca, R. M., 2000. Assessing achievement, affiliation, and power motives all at once: The Multi-Motive Grid (MMG). J. Pers. Assess. 74, $30 \quad 126-145$.

Soto, J.A., Levenson, R.W., 2009. Emotion recognition across cultures: the influence of ethnicity on empathic accuracy and physiological linkage. Emotion 9, 874-884. http://dx.doi.org/10.1037/a0017399

Tackett, J. L., Reardon, K. W., Herzhoff, K., Page-Gould, E., Harden, K. P., Josephs, R.A., 2015. Estradiol and cortisol interactions in youth externalizing psychopathology. 
1 Thompson, A. E., Voyer, D., 2014. Sex differences in the ability to recognize non-verbal

2 displays of emotion: A meta-analysis. Cogn. Emot. 28, 1164-1195.

3 http://dx.doi.org/10.1080/02699931.2013.875889

4 Viau, V., 2002. Functional cross-talk between the hypothalamic-pituitary-gonadal and- adrenal

5 axes. J. Neuroendocrinol., 14, 506-513. http://dx.doi.org/10.1046/j.1365-2826.2002.00798.x

6 Vongas, J. G., Hajj, R. A., 2017. The effects of competition and implicit power motive on men's 7 testosterone, emotion recognition, and aggression. Horm. Behav. 92, 57-71.

8 http://dx.doi.org/10.1016/j.yhbeh.2017.04.005

9 Waaramaa, T., 2017. Gender differences in identifying emotions from auditory and visual 10 stimuli. Logop. Phoniatr. Voco. 42, 160-166. https://doi.org/10.1080/14015439.2016.1243725

Wagner, H. L., 1993. On measuring performance in category judgement studies of nonverbal behaviour. J. Nonverbal Behav. 17, 3-28. http://dx.doi.org/10.1007/BF00987006

Wells L. J., Gillespie S. M., Rotshtein, P., 2016. Identification of emotional facial expressions: effects of expression, intensity, and sex on eye Gaze. PLoS ONE 11, e0168307. https://doi.org/10.1371/journal.pone.0168307

17 Welker, K.M., Lozoya, E., Campbell, J.A., Neumann, C.S., Carré, J.M., 2014. Testosterone, 18 cortisol, and psychopathic traits in men and women. Physiol. Behav. 129, 230-236. 19 https://doi.org/10.1016/j.physbeh.2014.02.057

20 Wendt, B., Scheich, H., 2002. The "Magdeburger Prosodie Korpus" - a spoken language corpus for fMRI-Studies, in: Bel, B., Marlien, I. (Eds.), Speech Prosody (pp.699-701). Aix-enProvence: SproSIG

Williams, L. M., Mathersul, D., Palmer, D. M., Gur, R. C., Gur, R. E., Gordon, E., 2009. Explicit identification and implicit recognition of facial emotions: I. Age effects in males and females across 10 decades. J. Clin. Exp. Neuropsychol. 31, 257-277. 26 http://dx.doi.org/10.1080/13803390802255635

27 World Medical Association (2013). World Medical Association Declaration of Helsinki: ethical 28 principles form medical research involving human subjects. JAMA 310, 2191-2194. 29 http://dx.doi.org/10.1001/jama.2013.281053 